\title{
Improve the Octane Number of Gasoline and Studying the effect of Reid vapor pressure and Calorific Value by using Environmental additives
}

\author{
Shahad Al-Obaidi ${ }^{a *}$ and Husham Al-Tameemi ${ }^{a}$ \\ ${ }^{a}$ Faculty of Engineering - University of Al-Qadisiyah-Iraq
}

\section{A R T I C LE INFO}

\section{Article history:}

Received 16 June 2019

Received in revised form 15 July 2019

Accepted 16 July 2019

\section{Keywords:}

Octane number

Reid vapor pressure

Calorific Value

Di-isopropyl Ether

Olive Oil

Aniline

\begin{abstract}
A B S T R A C T
An assessment was made for the impact resulted by the addition of (mixing of Di-isopropyl Ether with Olive Oil (DO)) and (mixing of Di-isopropyl Ether, Olive Oil and Aniline (DOA)) on the octane number as well as Reid vapor pressure (RVP) of gasoline with different chemical compositions. The locally produced gasoline is blended with three different ratios (v/v) of the additives, i.e. 8,10 and $15 \%$. It was observed that the octane rate of gasoline increased continuously and linearly with the addition of (mixing of Di-isopropyl Ether and Olive Oil (DO)) and (mixing of Di-isopropyl Ether, Olive Oil and Aniline (DOA)). The DOAgasoline blends produced higher gasoline octane number. The two additives noted a significant reduction in RVP and CV of the original fractions when blended with gasoline. However, additives were add in $(8,10$, $15 \%$ vol) to gasoline blend, increasing RON was (0.9-23.9).
\end{abstract}

(C) 2019 University of Al-Qadisiyah. All rights reserved.

\section{Introduction}

Gasoline, also called petrol or gas, is defined as a combination of volatile, flammable liquid hydrocarbons, derived from petroleum and used to internal combustion engines as fuel. Another use of it as a solvent for fats and oils, originally a byproduct for petroleum industry (kerosene being the main product), gasoline became the favorite vehicle fuel because of its ability to mix readily with air in a carburetor and high energy of combustion [1]. Gasoline, like other hydrocarbons, does not ignite in its liquid state, as it must first evaporate and mix with oxygen to ignite [2]. Where it is derived from oil, it is also the most popular producer and forms the bulk of the product which got per barrel of crude oil [3]. The composition of gasoline (\% volume) varies widely depending on refining processes and the crude oil used and the overall balance of demand for products [4]. The typical structure of hydrocarbons in gasoline is shown in Table $\mathbf{1}$.
Octane number is defined as one of the most paramount characteristics of gasoline currents and is a measure of its knock resistance property. Another definition is the percentage of the volume of i-octane in a blend of i-octane and n-heptane, which produces the same knock incisiveness caused by the fuel test under standard test circumstances in an (ASTM) internal combustion engine. The ASTM defined various kinds of octane number: motor octane number (MON) and research octane number (RON), which are an assessment by using ASTM tests D2700 for (MON) and ASTM D2699 for (RON) [5]. The self-ignition of fuel causes a knocking impact in gasoline engines. Knocking is a severe, pinging sound due to the combustion of the air-fuel mixture in the cylinder, it increases the risk of engine damage and reduces engine efficiency. Spark-ignition engines have been modeled to burn gasoline in a controlled process termed deflagration,

\footnotetext{
* Corresponding author.

E-mail address: shahadmahdi2015@gmail.com (Shahad Al-Obaidi)
} 


\begin{tabular}{|llll|}
\hline \multicolumn{2}{|l|}{ Nomenclature } & & \\
Add. & Additive & MTBE & Methyl Tert-Bbutyl Ether \\
AKI. & Antiknock Index & OO $_{\mathrm{x}}$ & Nitrogen Oxides \\
ASTM & American Society for Testing Material & ON & Octane Number \\
CV & Calorific Value & Ref. & Reformate \\
DIPE & Di-isopropyl Ether & RVP & Reid vapor pressure \\
DO & Mixture of ( Di-isopropyl Ether +Olive Oil) & RON & Cooperative Fuel Research \\
DOA & Mixture of ( Di-isopropyl Ether +Olive Oil + Aniline) & Sp.gr & Specific gravity \\
EDB & Ethylene Dibromide & SLN & Sweet Light Naphtha \\
H.N & Heavy Naphtha & TEL & Tetraethyl lead \\
L.N & Light Naphtha & US & United States \\
LSRN & Light Straight Run Naphtha & USEPA & US Public Health Service \\
MON & Motor Octane Number & vol. & Volume \\
\hline
\end{tabular}

where this process is significant in the timing of combustion, which could negatively be affected by the self-ignition of gasoline and result from the phenomenon commonly indicated as the engine knock [6, 7]. Generally, octane number increases with increasing the chain of branching and aromatics of carbon molecules and decreases with the chain length of carbon molecules. Straight chain alkanes like octane, heptane, and nonane ignite very easily and burst very soon, branching chain alkanes like $(2,2$, 4-tri methyl pentanes) iso-octane do not tend to self-ignite and cyclic compounds contain octane number higher of compounds of the straight chain $[8,9]$.

In the early twentieth century, motor engineers found out that engines without knock will work more efficiently and smoothly. Thomas Midgley A research scientist at the Dayton Research Laboratories in Dayton, Ohio, has found in 1916 that adding iodine to gasoline has significantly decreased motor knocks. A joint research work between Midgley and Charles Kettering (inventor of the electric self-start device) was conducted in 1917, where they mixed ethyl alcohol (grain alcohol) with gasoline and they concluded that such alcohol blended with gasoline could produce suitable fuel for cars. In December 1921 Midgley found out anti-knocks characteristics of tetraethyl lead (TEL). In 1923 TEL began manufacturing with a petite operation in Dayton, Ohio which produced nearly $600 \mathrm{~L}$ of the TEL per day [10]. US Public Health Service (USPHS) mentioned that each liter of burning gasoline would emit 1 gram of lead oxide that would accumulate at a grave level along the heavily traveled roads. In early 1970 s past century briefly, (EDB) Ethylene Dibromide has been added to leaded gasoline to decrease the harmful impact of lead on vehicle engines. A new use is found by EDB manufacturers of this chemical as a pesticide Because of the outlaws. Prohibition of the use of gasoline that contains lead of highway cars in the United States as of 1 January 1996 [11]. The oxygenates has been widely used in gasoline until 1979, when methyl tert-butyl ether (MTBE) has been added to gasoline to replace (TEL) and increases the fuel octane rate. Through intensive negotiations among the oil industry representatives, cars and USEPA, state officials, gasoline retailers, environmental organizations, oxygen suppliers, and consumer groups and as a portion for the Clean Air Act Amendments of 1990 [12]. At present, ethanol becomes a substantial portion of the alternative fuel market particularly in Brazil, USA, Australia and Sweden and other countries [13]. Ethanol and ethanol-gasoline mixtures are burned cleanly and contain greater levels of octane than pure gasoline, and there results less carbon monoxide and unburned hydrocarbon. Carbon monoxide represents a direct threat to human health ,also precursor ozone. Ethanol fuel contains a high temperature of evaporation, which decreases the temperature inside the cylinder, reduces $\mathrm{NO}_{\mathrm{x}}$ emissions and increases engine power. On the other hand, it has greater evaporative emissions from distribution equipment and fuel tanks. The emissions of evaporative contribute to the formation of smog and ozone at ground level [14]. In general, the impact of ethanol on $\mathrm{NO}_{\mathrm{x}}$ and $\mathrm{CO}$ emissions is minimal in newer engine emission control systems [15].

As it's known several chemical additives have been used to improve the octane number of gasoline, but the using of natural substances in mixed with chemicals as additives has not been tried so far. The aim of using these additives is to improve the internal combustion engines octane number and decrease air pollution.

Table 1. Typical structure of hydrocarbons in gasoline ( $\%$ volume)

\begin{tabular}{ll}
\hline The typical structure of hydrocarbons in gasoline & \% volume \\
\hline Alkanes & $4-8$ \\
Alkenes & $2-5$ \\
Benzene & $0.5-2.5$ \\
Cycloalkanes & $3-7$ \\
Cycloalkenes & $1-4$ \\
Isoalkanes & $25-40$ \\
Total Aromatics & $20-50$ \\
\hline
\end{tabular}

\section{Materials and Experimental Procedure}

\subsection{Materials}

1- Gasoline (Ref. and SLN)

Reformate and Sweet Light Naphtha are obtained from Al-Daura refinery in Iraq .

2- DIPE and Aniline of $99.95 \%$ purity are of analytical reagent grade and are obtained from SIGMA COMPANY.

3- Olive Oil is obtained from local markets.

\subsection{Experimental Procedure}

\subsubsection{First Stage}

Preparation of Gasoline Pool and Additives. The gasoline pool contains $50 \%$ vol of Ref. and $50 \%$ vol of LSRN. The preparation of additives include 
mixing of (95\% DIPE and 5\% Olive Oil) and mixing of (30\% DIPE ,2\% Olive Oil and $68 \%$ Aniline) are as follow:

1- $7 \mathrm{~L}$ of gasoline pool are blended in a bowl had fitting cover with stirring using the rod at refrigerator temperature $\left(5^{\circ} \mathrm{C}\right)$, for reduce fumigation of the volatile components.

2- $400 \mathrm{ml}$ of the first additive are blended in a bowl had fitting cover with stirring using the rod at refrigerator temperature $\left(5^{\circ} \mathrm{C}\right)$.

3- $400 \mathrm{ml}$ for the second additive are blended in a bowl had fitting cover with stirring using the rod at refrigerator temperature $\left(5^{\circ} \mathrm{C}\right)$.

\subsubsection{Second Stage}

The prepared additives are used at various volume percentages. All the prepared additives are tested during the preparation of the gasoline pool of the blends as follows:

1- Reid vapor pressure (RVP) and Octane number (ON) of gasoline pool are measured by RVP measurement and CFR engine before adding the compounds (the additives).

2- Three glass containers are filled with $(92 \%, 90 \%, 85 \%)$ of gasoline pool and added (DO) in different concentrations $(8 \%, 10 \%$, and $15 \%)$ with shaking by using a rod.

3- The Reid vapor pressure and octane number for these blends are measured by apparatus Reid vapor pressure measurement and CFR engine. 4- Repeat steps 2 and 3 above with (DOA) additives.

Table 2. Laboratory testing of Al-Daura Refinery Petroleum Cuts

\begin{tabular}{llllll}
\hline Sample & L.N & Feed & Bottom & H.N & Reformate \\
\hline Sp.Gr & 83.5 & 64.5 & 64.9 & 60.4 & 52.5 \\
RVP & 17.3 & & & & 6.6 \\
Distillation & & & & & \\
I.B.P & 32 & 48 & 54 & 82 & 44 \\
$5 \%$ & 36 & 56 & 62 & 92 & 60 \\
$10 \%$ & 40 & 66 & 70 & 98 & 72 \\
$20 \%$ & 46 & 74 & 78 & 104 & 82 \\
$30 \%$ & 54 & 86 & 89 & 110 & 94 \\
$40 \%$ & 62 & 98 & 102 & 116 & 106 \\
$50 \%$ & 68 & 108 & 114 & 124 & 116 \\
$60 \%$ & 76 & 116 & 122 & 132 & 126 \\
$70 \%$ & 84 & 124 & 128 & 140 & 134 \\
$80 \%$ & 90 & 132 & 136 & 144 & 144 \\
$90 \%$ & 94 & 144 & 146 & 148 & 152 \\
$95 \%$ & 98 & 152 & 154 & 158 & 162 \\
E.P & 120 & 174 & 176 & 180 & 190 \\
RON & 62 & & & & 90 \\
\hline
\end{tabular}

\subsection{Analysis Method}

The fuel properties of the blends tested are determined in accordance with the American Standard for Testing Materials (ASTM) procedures of the petroleum products.

\subsubsection{Cooperative Fuel Research Engines (CFR)}

(D2699)

is used to determine the octane number as follows:

A- A standard test engine and operating conditions are used to determine the Research Octane Number RON of a spark-ignition engine fuel to compare its knock properties by those of PRF blends of known RON. To produce a standard AKI for specimen fuel, the ratio of fuel to air is regulated, as measured by means of a specific electronic detonator instrument meter system. To maximize the AKI for each fuel, the fuel-toair ratio of the fuel specimen and each mix of the fundamental reference fuel blends is regulated.
B- The fuel-air ratio can be gotten for maximum AKI through:

1- Note the AKI equilibrium value for each step by making gradual changes in the power of the mixture, and then select the conditions that increase the reading.

2- The power of the mixture is changed from either rich to lean or lean to rich at a fixed rate and so via selecting the maximum of AKI. The device is shown in Fig. 1.

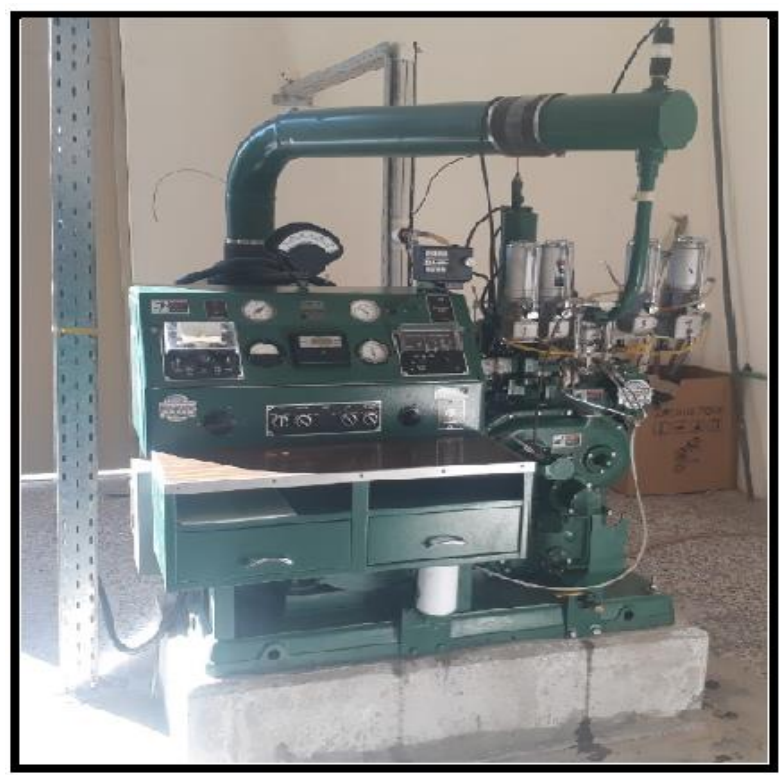

Figure 1. Show Research Method Test Engine

\subsubsection{Standard Test Method of the Vapor Pressure for} Products Petroleum (Reid Method) (D323)

is used to determine the Reid vapor pressure as follows:

A- How to prepare the sample for testing:

The bottle is filled with $80 \%$ of its size and then closed, placed in a water bath until it reaches $\left(0^{\circ} \mathrm{C}\right)$ and then open and return to the water bath and repeat this process 3 times.

B- Method of examination:

Fill the form into the product and close it tightly and place it inside the tub, check by pressing the test button. The reading is taken from the screen corresponding to the same number for the chamber after it is constant.

The device is shown in Fig. 2.

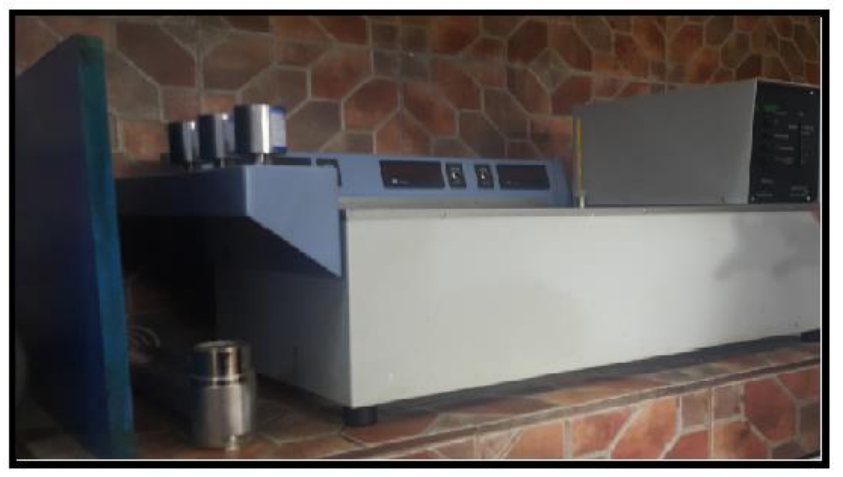

Figure 2. Reid Vapor Pressure Test Engine 


\section{Results and Discussions}

In this study, olive oil (5 and 2 vol.\%) are selected and mixed with other additives. The gasoline combustion engine, in this case, leads in both an increase in fuel mileage and reducing harmful emissions. The addition of olive oil to gasoline will improve combustion efficiency and thus reduce $\mathrm{CO}_{2}$ emissions, while the addition of DIPE (oxygenate compound) increases $\mathrm{CO}_{2}$ because of the complete combustion and decrease $\mathrm{CO}$. This may be due to smaller combustion produces an increase in oxygenate content when DIPE increases in the blends. The smaller combustion reduces carbon monoxide emissions in the exhaust gas. This means that the addition of olive oil with DIPE to gasoline is to reduce the $\mathrm{CO}_{2}$ that increases with the addition of DIPE alone to gasoline [16, 17]. The following study effectiveness of (DO and DOA) on the octane number, Reid vapor pressure, and Calorific value.

\subsection{Research Octane Number (RON)}

One of the expected tests for appraisal the octane number, as characterized in ASTM D2699, Research Octane Number, using a single drum engine running at $600 \mathrm{rpm}$. Results of the RON tests shown in Table 3. for the addition (DO and DOA) to gasoline pool.

Table 3. Results of RON when Blending (DO, DOA) with gasoline pool

\begin{tabular}{lcccc}
\hline RON of (DOA) & $\begin{array}{l}\text { Blend } \\
\text { Number }\end{array}$ & $\begin{array}{l}\text { RON } \\
\text { of } \\
\text { (DO) }\end{array}$ & $\begin{array}{l}\text { Blend } \\
\text { Number }\end{array}$ & $\begin{array}{l}\text { Blending } \\
\text { Ratio }\end{array}$ \\
\hline 100\% asoline + 0\% Add. & 1 & 76 & 1 & 76 \\
$92 \%$ gasoline + 8\% Add. & 2 & 76.9 & 5 & 99.5 \\
$90 \%$ gasoline + 10\% Add. & 3 & 77.5 & 6 & 97.5 \\
$85 \%$ gasoline + 15\% Add. & 4 & 79.2 & 7 & 99.6 \\
\hline
\end{tabular}

The RON values of tested gasoline blends with (DO) started with $8 \%$ of (DO) and $92 \%$ of gasoline pool (shown in Fig. 3.), it was found that the octane rating was continuously and linearly increased with a range of 0.8 of blending ratio but the increase will be slightly also when increasing the proportion of additives up to $15 \%$ give RON equal to 79.2 .

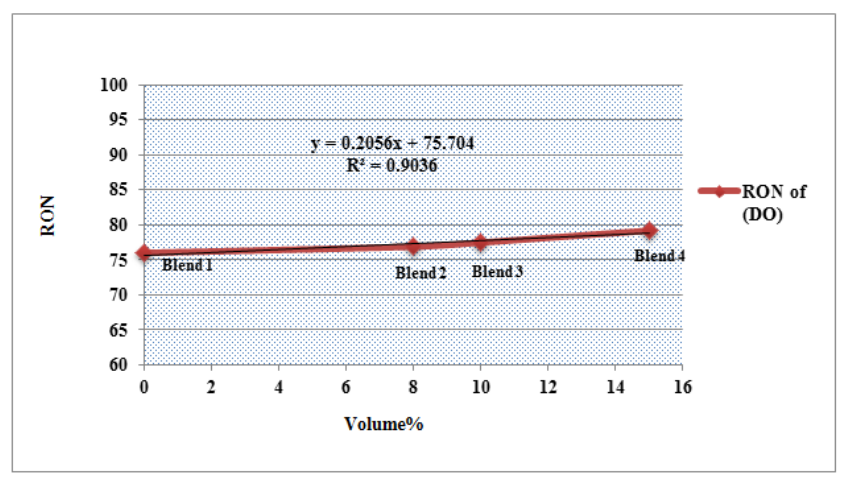

Figure 3. RON value of the gasoline with the ratio of (DO) additive

The increasing of the (DOA) until $15 \%$ of the blending samples increase RON number slightly reaching to 99.6 and this increase is due to the presence of aniline with olive oil and di-isopropyl ether, where Aniline is characterized as an aromatics, which are characterized by the high fuel source of energy and high octane levels, and thus are able to achieve target values to the octane quality [18] but at $10 \%$ decrease to 97.5 due to a malfunction of the device when reading. The readings are shown in Fig. 4.

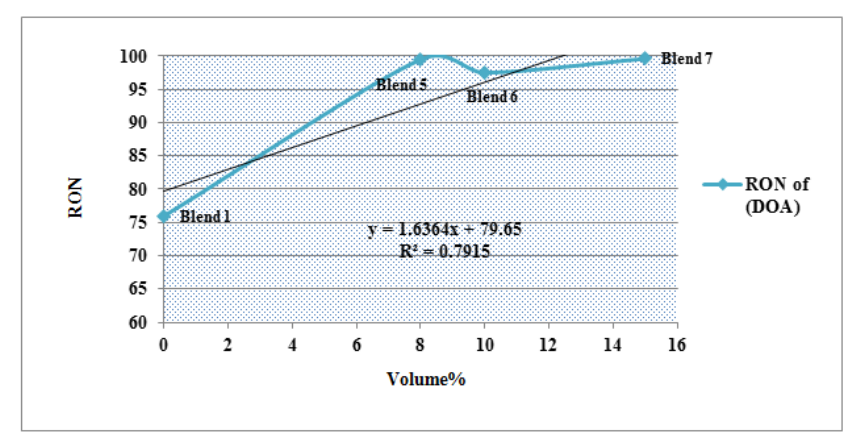

Figure 4. RON values of the gasoline along with the ratios of (DOA) additives

\subsection{Reid Vapor Pressure}

The results of the vapor pressure measured in psi unit at $37.8^{\circ} \mathrm{C}(\mathrm{RVP})$ of the original gasoline compositions and the ones structures with different percentages of compounds (additives) are presented in Table 4.

Table 4. Results of RVP when Blending (DO, DOA) with gasoline pool

\begin{tabular}{lcccc}
\hline RON of (DOA) & $\begin{array}{l}\text { Blend } \\
\text { Number }\end{array}$ & $\begin{array}{l}\text { RON } \\
\text { of } \\
\text { (DO) }\end{array}$ & $\begin{array}{l}\text { Blend } \\
\text { Number }\end{array}$ & $\begin{array}{l}\text { Blending } \\
\text { Ratio }\end{array}$ \\
\hline 100\% gasoline + 0\% Add. & 1 & 9.7 & 1 & 9.7 \\
$92 \%$ gasoline + 8\% Add. & 2 & 8.01 & 5 & 8.4 \\
$90 \%$ gasoline + 10\% Add. & 3 & 7.4 & 6 & 7 \\
$85 \%$ gasoline + 15\% Add. & 4 & 7.15 & 7 & 6.5 \\
\hline
\end{tabular}

The RVP values of tested gasoline blends with (DO) significantly reduce the Reid vapor pressure to 7.15 as shown in Fig. 5.

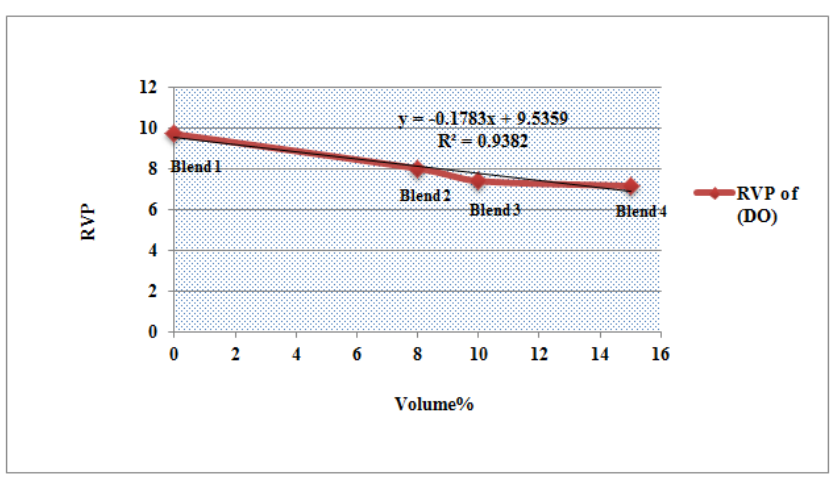

Figure 5. RVP values of the gasoline with ratios of (DO) additive

and with (DOA) decreasing the RVP to 6.5 as shown in Fig. 6. This decrease in RVP when adding di-isopropyl ether to gasoline is due to its high molecular weight and has low fluctuations. Similarly, the addition of olive oil also reduced RVP due to its high density [19]. 


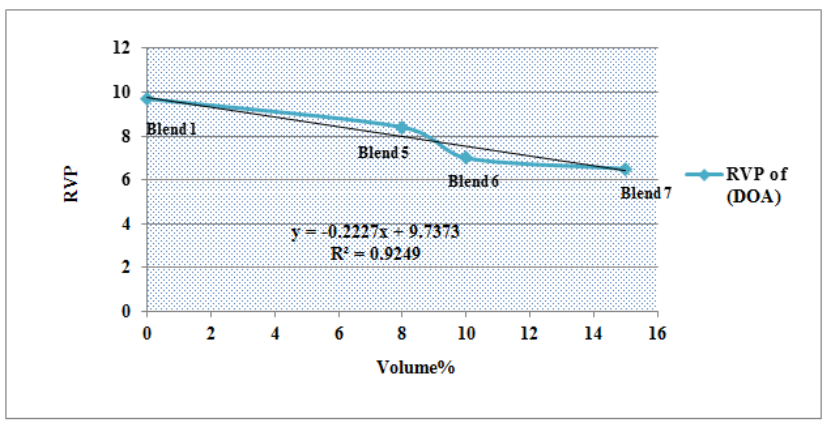

Figure 6. RVP values of the gasoline with the ratios of (DOA) additives

\subsection{Calorific Value}

The results of the Calorific Value in Kcal/kg (shown in Table 5. ) is calculated theoretically depending on the bellow equation :

Calorific Value (CV) = [12400- (2100(sp.gr.)2)] [20].

Table 5. Results of RVP when Blending (DO, DOA) with gasoline

pool

\begin{tabular}{lllll}
\hline $\begin{array}{l}\text { RON of } \\
\text { (DOA) }\end{array}$ & $\begin{array}{l}\text { Blend } \\
\text { Number }\end{array}$ & $\begin{array}{l}\text { RON of } \\
\text { (DO) }\end{array}$ & $\begin{array}{l}\text { Blend } \\
\text { Number }\end{array}$ & $\begin{array}{l}\text { Blending } \\
\text { Ratio }\end{array}$ \\
\hline $\begin{array}{l}\text { 100\% gasoline } \\
+0 \% \text { Add. }\end{array}$ & 1 & 11350.32 & 1 & 11350.32 \\
$\begin{array}{l}\text { 92\% gasoline }+ \\
\text { 8\% Add. }\end{array}$ & 2 & 11345.09 & 5 & 11295.70 \\
$\begin{array}{l}\text { 90\% gasoline }+ \\
\text { 10\% Add. }\end{array}$ & 3 & 11343.77 & 6 & 11281.83 \\
$\begin{array}{l}\text { 85\% gasoline }+ \\
15 \% \text { Add. }\end{array}$ & 4 & 11340.50 & 7 & 11246.77 \\
\hline
\end{tabular}

The specific gravity of the gasoline and additives is determined using the values of the densities of the samples obtained by the ASTM (D287) method. The $\mathrm{CV}$ values of tested gasoline blends with (DO) that significantly reduce the Calorific Value from 11350.32 to 11340.50 as shown in Fig. 7. and with (DOA) decreasing the CV to 11246.77 as shown in Fig. 8.

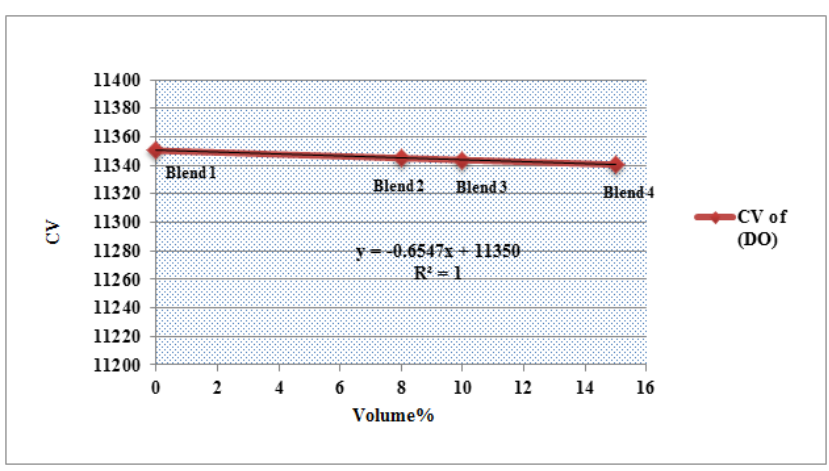

Figure 7. CV values of the gasoline with ratios of (DO) additive

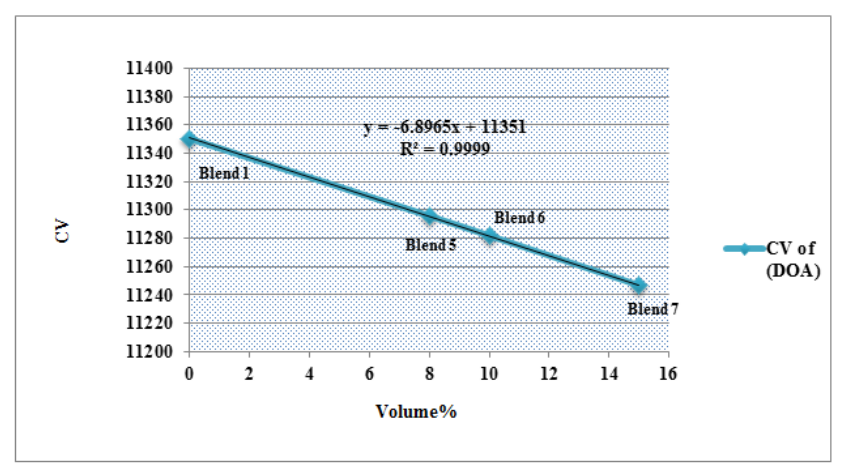

Figure 8. CV values of the gasoline with ratios of (DOA) additive

However the effect of additional olive oil with Aniline has enhanced the octane number of the blending gasoline due to carbon bonds in the aniline compound tend to give an addition reactions of free oxygen radical or $\mathrm{H}$ free radical, $\mathrm{OH}$ free radical or $\mathrm{HO}_{2}$ radicals [21].

The disadvantage of using Aniline alone as gasoline additive is considered as Carcinogenic and Courses hemolysis additive [22], but blending Aniline with olive oil ( which can be considered as green oil ), in addition it has a high octane number and (DIPE) can decrease the harmful and carcinogenic emissions as a result of decreasing the aniline ratio in the blending samples as shown Table 6.

Table 6. Aniline Ratios used in (DOA) additive in the total Blending sample ratio

\begin{tabular}{ll}
\hline RON of (DOA) & Blend Number \\
\hline $100 \%$ gasoline + 0\% DOA & 0 \\
$92 \%$ gasoline + 8\% DOA & 5.44 \\
$90 \%$ gasoline + 10\% DOA & 6.8 \\
$85 \%$ gasoline + 15\% DOA & 10.2 \\
\hline
\end{tabular}

\section{Conclusions}

Depending on the analytics discussed earlier, conclusions can be drawn in the following:

The prepared component mixtures act positively to improved the octane number.

- By looking at the results shown in the figures, the increase in the octane number was obtained with DOA more than with the presence of DO, indicating a clear effect of the aniline on the increase.

- (DOA) is the best prepared component mixtures for improve octane number where it rises octane number from 76 to 99.5 at concentration $8 \%$.

- The preparation component mixtures reduce the RVP.

- RVP for gasoline after all additions with various concentrations were found within the limits assigned by ASTM.

- The effect of adding olive oil is clear by reducing the Reid vapor pressure because of its high density.

- The Calorific value of (DOA) is decreased that means we can get an additive that gives a characteristic similar to the fuel or better.

- The advantage of the using Aniline as a gasoline additive in the mixture of (DOA) instead of pure Aniline is : (decreasing harmful emission on the environment) and represent an environmentally friendly additive. 


\section{REFERENCES}

1. Ezeldin, M. and A. Massad, Quality improvement of Sudanese gasoline by using di isopropyl ether and moringa oil. European academic research, 2015. 3(3): p. 2748-2763.

2. Leffler, W.L., Petroleum refining in nontechnical language. 2008: PennWell Books.

3. Demirbas, A., et al., Octane rating of gasoline and octane booster additives. Petroleum Science and Technology, 2015. 33(11): p. 1190-1197.

4. Harper, C. and J.J. Liccione, Toxicological profile for gasoline. 1995.

5. Seddon, D., Octane Enhancing Petrol Additives/Products: Literature Review and Analysis. Victoria, 2000. 3930.

6. Balaban, A., L. Kier, and N. Joshi, Structure-property analysis of octane numbers for hydrocarbons (alkanes, cycloalkanes, alkenes). MATCH Commun. Math. Comput. Chem, 1992. 28: p. 13-27.

7. Rothamer, D.A. and J.H. Jennings, Study of the knocking propensity of 2, 5-dimethylfuran-gasoline and ethanol-gasoline blends. Fuel, 2012. 98: p. 203-212.

8. Mendes, G., H.G. Aleme, and P.J. Barbeira, Determination of octane numbers in gasoline by distillation curves and partial least squares regression. Fuel, 2012. 97: p. 131-136.

9. Yasin, G., et al., Analytical studies on the quality and environmental impact of commercial Motor gasoline available in Multan region of Pakistan. Pakistan Journal of Analytical \& Environmental Chemistry, 2008. 9(2): p. 8.

10. Lincoln, K., The secret history of lead: special report. The Nation March, 2000. 20: p. 11-45.
11. Thomas, V., The elimination of lead in gasoline. Annual Review of Energy and the Environment, 1995. 20(1): p. 301-324.

12. Nadim, F., et al., United States experience with gasoline additives. Energy Policy, 2001. 29(1): p. 1-5.

13. Kheiralla, A.F., et al., Effect of ethanol-gasoline blends on fuel properties characteristics of spark ignition engines. University Of Khartoum Engineering Journal, 2011. 1(2).

14. Yüksel, F. and B. Yüksel, The use of ethanol-gasoline blend as a fuel in an SI engine. Renewable energy, 2004. 29(7): p. 1181-1191.

15. Unnasch, S. and A. Henderson, Change in Air Quality Impacts Associated with the Use of E15 Blends Instead of E10. 2014.

16. Dhamodaran, G., G.S. Esakkimuthu, and Y.K. Pochareddy, Experimental study on performance, combustion, and emission behaviour of diisopropyl ether blends in MPFI SI engine. Fuel, 2016. 173: p. 37-44.

17. Theaker, W.E., Fuel additive. 2011, Google Patents.

18. Kaiser, C.R., et al., Quality control of gasoline by $1 \mathrm{H}$ NMR: aromatics, olefinics, paraffinics, and oxygenated and benzene contents. Fuel, 2010. 89(1): p. 99-104.

19. Da Silva, R., et al., Effect of additives on the antiknock properties and Reid vapor pressure of gasoline. Fuel, 2005. 84(7-8): p. 951-959.

20. Sheet, E.A.E., Improvement of gasoline octane number by blending gasoline with selective components. 2008, MSc. Thesis, University of Technology.

21. Boot, M.D., et al., Impact of fuel molecular structure on auto-ignition behavior-Design rules for future high performance gasolines. Progress in Energy and Combustion Science, 2017. 60: p. 1-25.

22. Yokel, R.A. and J.S. Crossgrove, Manganese toxicokinetics at the blood-brain barrier. 2004. 